\title{
From Electric Shocks to the Electoral College: How Boredom Steers Moral Behavior
}

\author{
Meltem Yucel \\ Department of Psychology, University of Virginia
}

Erin C. Westgate

Department of Psychology, University of Florida

$* * *$ Preprint $* * *$

To appear in A. Elpidorou (Ed.), The Moral Psychology of Boredom. London: Rowman \& Littlefield. 


\section{From Electric Shocks to the Electoral College: How Boredom Steers Moral Behavior}

Among charming tales of quirky haircuts conjured up out of boredom, lurk more chilling stories. On June, 2017, motorists in Ireland were disturbed by an odd sight: a man on a bridge, aiming a gun. When police arrived, they found a teenager, perched above an Irish highway overpass, centering passing cars in the sights of his $6 \mathrm{~mm}$ air rifle. When asked later in court, he explained simply: he was "bored" (Ferguson and McLean 2019). Although boredom has been associated with prosocial behavior (e.g., van Tilburg and Igou 2017), it has also been associated with a wide array of morally questionable and disturbing outcomes, including self-harm (Nederkoorn et al. 2016), reckless driving (Steinberger et al. 2017), and sadism (Pfattheicher et al. 2020).

We all experience boredom, from being stuck in airport security lines to reading poorly written book chapters. But what is boredom, why do we experience it, and what happens when we do? We suggest a new take on this everyday emotion as an important and useful cue that we are not cognitively engaged in meaningful experiences. According to the Meaning and Attentional Components (MAC) model of boredom, people feel bored when they cannot successfully engage their attention in meaningful activities. Boredom can be painful, but it provides important feedback about our lives, by signaling a lack of meaningful attentional engagement. In short, boredom tells us whether we want to and are able to focus on what we are doing (or thinking), and then directs us towards behaviors that are more challenging or meaningful.

In doing so, boredom plays an important role in regulating moral thoughts and behaviors. Following recent calls urging researchers to consider boredom as a moral emotion (Elpidorou 2017), we explore how boredom influences our moral actions and perceptions. We start by 
reviewing how emotions (broadly) impact morality, and when and how positive and negative affect lead to moral behavior. We then zoom in on one specific form of negative affect boredom - and explore how feeling bored leads us to behave in more pro- or antisocial ways, depending on the environment.

\section{How Emotions Steer Morality}

Moral philosophers and psychologists have long been interested in the role of emotions in morality (Blair 1995; Haidt 2001; Hume 1896; Smith 1976; Yucel, Hepach, and Vaish 2020). One question, in particular, has centered many debates: do emotions precede our moral judgments, or do they follow afterwards, once moral judgments have been formed? Some have emphasized the causal role of reasoning in moral behavior (e.g., Kohlberg 1976), while others have stressed the causal role of emotions (e.g., Smith 1976).

Early developmental researchers such as Piaget and Kohlberg argued for a cognitive approach, where logic and reasoning give rise to our moral evaluations and acts. They proposed a stage-like progression of moral development, where each moral stage that children achieve corresponds to cognitive skills gained (Kohlberg 1976; Piaget 1960). Although their primary focus was on cognition, even Kohlberg (1964) does not dismiss the possibility that emotions are involved in morality.

Emotivists, on the contrary, place a strong emphasis on the importance of emotions (or "affect," more generally) as the source of morality. While emotions refer to discrete states, tied to a specific eliciting situation (e.g., "anger," "awe"; Clore and Ortony 2013), affect refers to general feelings of goodness or badness, tied to interoceptive perceptions of physiological change (e.g., racing pulse; Barrett 2017). More specifically, emotivists have argued for the 
centrality of emotions in drawing a distinction between the moral and nonmoral (Hume 1896; Nichols 2002, 2004; Prinz 2006, 2007; Smith 1976). For example, Hume (1896) and Smith (1976) argued that emotions serve as an internal compass from which moral reasons are derived. If we feel bad when others physically hurt us, these negative feelings will coalesce as moral judgments and make us perceive hitting as immoral.

Similarly, Haidt (2001) claimed that adults form moral judgments based primarily on affective intuitions. Consider, for instance, the decision of whether to have sex with your sibling. Rather than relying on reasoned moral judgment, people instead rely on their quick intuitive feelings of repulsion to reject the idea of two siblings having sex. Haidt argues that people come up with post hoc reasons only after reacting to moral situations, or what he terms "the emotional dog and its rational tail" (814). For instance, in moral dumbfounding experiments, adult participants typically respond to moral scenarios (such as consensual incest) with condemnation, even when they do not have rational reason for doing so (Haidt, Björklund, and Murphy 2000). Although theorists may disagree on the degree to which emotions are involved in what we perceive as moral or how we act in righteous ways, most agree that emotions do play an important role in morality. Emotions influence our perceptions of what is moral, direct our attention towards actions that are (im)moral, and motivate us to behave in (im)moral ways (Prinz and Nichols 2010). Below we briefly consider how emotions influence perception, motivation, and behavior, before turning to the case of one emotion in particular: boredom.

\section{Emotions steer moral attention}

How do we know an action is immoral? As the previous section highlights, emotions and affect play an important role in how we construe morality. But before we can categorize an act as moral 
or immoral, we first need to attend to it. Affective arousal, together with situational factors, directs our attention — much like a spotlight — to affect-inducing events in our environment. For instance, feeling fearful upon seeing a snake may lead us to consciously notice the snake and direct our attention towards possible escape routes (or rocks with which to defend ourselves). These embodied experiences of affect then influence our judgments and even memory (Peters et al. 2006; Storbeck and Clore 2008).

Little work has investigated whether affect is present in our perceptions of (and responses to) immoral acts. In a recent study we investigated the role of affect in developing this moral/nonmoral distinction (Yucel, Hepach, and Vaish 2020). If emotions are integral to morality, we reasoned, then violating a moral norm (e.g., against non-violence) should elicit more emotion than violating a non-moral or conventional norm (e.g., wearing shoes at work). Therefore, we randomly assigned young children and adults to watch a video of either a moral norm violation (e.g., a person destroying someone else's artwork) or a non-moral norm violation (e.g., a person playing a game incorrectly; Yucel, Hepach, and Vaish 2020). We recorded participants' physiological responses by measuring how much their pupils dilated as they watched these videos. Physiological arousal, in the form of pupil dilation, is an important marker of emotionality, and a sign that participants were experiencing more intense affect (Bradley, Miccoli, Escrig, and Lang 2008). Across all age groups, witnessing moral violations resulted in greater physiological arousal (i.e., pupil dilation) than witnessing a nonmoral violation. We concluded that affective arousal is not only present to a greater degree when it comes to moral actions, but that even young children draw such emotional distinctions between moral and nonmoral rules. Research with older children corroborates this relationship between emotions 
and morality; children rate moral violations to be more affectively negative than nonmoral (conventional) violations (Arsenio and Ford 1985).

Just as moral violations evoke more powerful emotions, so too do affective reactions indicate that a moral violation has occurred. According to an enormously influential theory in emotion, affect acts as “information” about its perceived object (affect-as-information; Clore, Gasper, and Garvin 2001; Clore and Tamir 2002). We assume that what feels good is good, and that what feels bad is bad. Feeling distress upon seeing a person rip up someone else's artwork thus lends moral judgment to the event: destroying other people's property must be a "bad" thing to do. Furthermore, discrete emotions provide more fine-grained information than core affect (e.g., valence and arousal). Anger, for instance, is elicited when someone intentionally does something blame-worthy; thus feeling anger is a sign that morally suspect behavior has occurred (Ortony, Clore, and Collins 1988). Thus, all emotions that include approval or disapproval of one's own behavior (or the behavior of others), as one of their eliciting components, are likely to be moral emotions. This includes emotions in response to both positive praiseworthy (e.g., pride, admiration, gratitude) as well as negative blameworthy (e.g., anger, shame, guilt) behavior. Taken together, affect directs our attention to moral events, and helps us distinguish moral from non-moral (conventional) concerns.

\section{Emotions motivate (im)moral behavior}

Emotions not only direct attention and interpretation of moral events, but also motivate us to behave in (im)moral ways. For example, anger can motivate us to act in both morally good (e.g., to protect those who have been hurt) and bad ways (e.g., to hurt those who have engaged in wrongdoing). Affect influences our reactions by motivating us to act on our feelings. Upon 
witnessing a moral transgression, for instance, we might feel more compassion towards the victim (e.g., experience affective arousal) and offer to help, to decrease our own arousal. For instance, people who paid more attention to the news after the 2016 presidential election of Donald Trump felt more anger, but were also more likely to take political action, due to that anger (Ford et al. 2018).

Contrary to popular wisdom, emotions do not "trigger" behaviors directly, but rather do so via an indirect push-and-pull reminiscent of operant conditioning. People are generally motivated to maintain positive affective states (and reduce negative ones) in an effort to feel good. Just as rats will press a lever in anticipation of the food pellet they expect to receive, so too do people select actions in anticipation of the emotions they expect to experience as a consequence. Consider anger. Despite popular conceptions, feeling angry does not inherently make people violent. But if, upon being insulted, a person 1) feels great anger and 2) believes that violence will reduce that anger and 3) that violence constitutes a socially acceptable response, they are likely to lash out aggressively at the perpetrator (e.g., Cohen and Nisbett 1994; Cohen et al. 1996). Because of this, there is no one-to-one mapping between emotion and behavior; rather, people's behavior depends on what they feel at the moment, the options available, and the perceived affective consequences of each option. What people do depends on what they want to feel (Tamir and Ford 2012).

This is also true in the moral domain. For instance, prosocial behavior has been linked to both positive and negative affect (e.g., boredom). In other words, feeling good and feeling bad can both make people behave prosocially (Lyubomirsky, King, and Diener 2005; Cialdini and Fulz 1990; Van Doorn, Zeelenberg, and Breugelmans 2014). People are more likely to help others after being surprised with a cookie or finding a dime in a phone booth, because surprises 
make us feel good (Isen and Levin 1972; Cunningham, Steinberg, and Grev 1980). Likewise, recalling happy events increases blood donation (O’Malley and Andrews,1983); reading moodboosting messages increases volunteering, charitable donations and helping behavior (Aderman 1972; Cunningham, Steinberg, and Grev 1980), and feeling grateful increases willingness to help even at personal expense (Bartlett and DeSteno 2006). Finally, environmental features that induce positive moods, such as attractive fragrances and lighting, prolong how long people are willing to help for (Baron and Bronfen 1994; Baron, Rea, and Daniels 1992). If positive moods increase helping by making it more pleasant, negative moods may also make us more likely to help, because helping others makes us feel better (i.e., negative-state relief hypothesis; Cialdini, Darby, and Vincent 1973). For instance, thinking about sad experiences makes teenagers (though not younger children) more likely to help (Cialdini and Kenrick 1976), and experiencing failure leads adults to help if doing so is especially easy or valuable (Benson 1978; Weyant 1978).

Beyond core affect, specific discrete emotions can also directly motivate moral behavior (or the lack thereof). People help others when they feel an emotional response to their distress, and refrain from harm when the thought of others' suffering pains them. Even young children are motivated to behave prosocially in response to such feelings. For instance, 2-year-olds exhibit physiological arousal (measured via changes in pupil dilation) upon seeing someone in need ( Hepach, Vaish, and Tomasello 2012). This arousal quickly decreases if the child (or another person) is able to help the adult in need. However, if children are held back from helping, their arousal remains elevated (Hepach, Vaish, and Tomasello 2012). Furthermore, 2-year-olds' with higher arousal are faster to help an adult in need (Hepach et al. 2016). In contrast, in the absence of such emotional distress, people behave prosocially only if they expect rationally to benefit from doing so (i.e., empathy-altruism hypothesis; Batson and Shaw 1991). 
Other specific emotions that convey moral information (and motivate strategies to remedy moral wrongs) include anger, guilt, and shame (Čehajić-Clancy et al. 2016). For instance, anger in response to specific incidents increases prosocial behavior to address perceived wrongs - people who experience more anger and outrage in response to moral violations are more likely to support, spend time with, and compensate perceived victims (Montada and Schneider, 1989; Iyer, Schmadel, and Liker 2007;) and more likely to punish wrongdoers (Lotz et al. 2011; Vitaglione and Barnett 2003; van Doorn, Zeelenberg, and Breugelmans, 2014). Likewise collective guilt and shame predict endorsement of reparations to indigenous groups among Chileans (Brown et al. 2008) and to Bosnian Muslims among Bosnian Serbs (Brown and Cehajic 2008).

In sum, affect and emotion steer our attention towards morally-relevant actions, inform us whether actions are moral, and motivate us to behave in both moral and immoral ways. They do this by providing a self-reinforcing system for morality, incentivizing "good" behavior with positive emotions (e.g., pride, gratitude) and "punishing" bad behavior with negative ones (e.g., shame, guilt, anger). Below we turn to the question of how one specific negative emotion in particular—boredom — affects our moral perceptions and behaviors.

\section{How Boredom Steers Moral Decision-making}

As "situated affective appraisals," all emotions share an affective core-emotions are inherently positive or negative (Clore and Ortony 2013). That boredom is aversive may seem obvious, but is strong evidence for boredom's status as an emotion. Earlier theorizing held boredom to be a neutral state, neither positive nor negative (Gasper 2018; Gasper, Spencer, and Hu 2019). 
However, people routinely report boredom to be affectively negative (van Tilburg and Igou 2016; Goetz et al. 2006, 2014); they will pay to avoid it (Dal Mas and Wittmann 2017), and prefer even unpleasant experiences, including electric shocks and disturbing images, over feeling bored (Bench and Lench 2019; Haverman et al.,2015; Nederkoorn et al. 2016; Wilson et al. 2014).

Boredom is not only affective, it also shares other core features of emotions. Classical views posit the existence of a discrete set of core emotions, each triggering certain behaviors, and reliably mapping onto unique facial expressions, physiological features, and neural activity. However, recent data provide strong evidence against this approach (e.g., Barrett 2006). Rather than the one-to-one mapping suggested by classical theories, researchers find that specific emotions cannot be reliably identified by their facial expressions (Gendron et al. 2014a, 2014b; Barrett et al. 2019), physiological features (e.g., heart rate; Siegel et al. 2018), or neural activity in the brain (Lindquist et al. 2012). Instead, what does reliably distinguish specific emotions are the situational construals (or appraisals) that elicit them (e.g., Schachter and Singer 1962; Barrett 2006).

\section{The Origins of Boredom: Meaning and Attention}

If emotions are defined by the construals that elicit them, what reliably elicits boredom? Early theories of boredom focused on environmental elicitors; boredom was thought to be caused by lack of stimulation (e.g., Berlyne 1960; Cox 1980). However, it is unclear why understimulating environments would be boring. One explanation is that such environments make it hard to pay attention (e.g., Danckert and Merrifield 2016; Eastwood et al. 2012). However, understimulation is not the only situation that gives rise to inattention; overstimulation 
can also make it difficult to pay attention. Nor is lack of attention the only reason why something might be boring. A third set of theories focus on boredom's existential origins (e.g., Barbalet 1999; Locke and Latham 1990; van Tilburg and Igou 2012). To the extent that attention leads to boredom, such existential theories suggest, it is because the situation was meaningless to begin with.

There is good evidence that each of these- - understimulation, overstimulation, attention deficits, meaning deficits - play an important role in boredom, and each of these theories has made important contributions to understanding what boredom is and why we experience it. The MAC (Meaning and Attentional Components) model of boredom and cognitive engagement brings these individual theories together to reconcile competing predictions for the causal role of meaning and attention in producing boredom (Westgate and Wilson 2018). For instance, attentional theories predict that people should not be bored if they are successfully paying attention, even if what they are doing feels meaningless. Conversely, existential theories predict that people would feel bored under those circumstances, but should not feel bored if they have trouble paying attention during an otherwise meaningful task.

The MAC model tests these predictions empirically by experimentally manipulating both attention and meaning at the same time. By doing so, we can isolate the relative contributions of meaning and attention, and test whether the effects of attention on boredom are dependent on meaning (or vice versa) using the gold-standard test of causality: randomized control experiments. When meaning and attention are manipulated in this way, we find strong evidence for both the attentional and existential accounts of boredom (Westgate and Wilson 2018). In other words, attention deficits and meaning deficits both produce boredom, and do so equally. Nor do they interact; the effect of attention on boredom does not depend on meaning, and the 
effect of meaning does not depend on attention. Instead, people are bored if they are unable to pay attention, and they are bored if meaning is lacking; these effects stack. In other words, both attentional and existential theories get it (partially) right. People will feel bored if they are successfully paying attention, if what they are doing feels meaningless. But people will also feel bored if they have trouble paying attention during an otherwise meaningful task.

Further evidence that both attention and meaning play equal and independent roles in boredom comes from correlational data. Aggregating across 14 studies, we compared how well attention (versus meaning) deficits predict self-rated boredom across a variety of tasks (Westgate and Wilson 2018). After each task, people were asked to retrospectively rate how boring and meaningful the task was, and how hard it was to concentrate. By pitting attention and meaning against each other in this way, we were able to examine the relative contributions of each component, while statistically controlling for each other's presence. Once again, we found strong independent effects of meaning and attention. Greater difficulty paying attention predicted increased boredom (meta-analytic $r=.34$ ), even after controlling for how meaningful the task was. Likewise, the less meaningful the task felt, the more boredom people experienced (metaanalytic $r=.35$ ), even after controlling for attention. Again, there was no interaction, metaanalytic $r=.00$ : people were least bored when meaning and attention were high, and most bored when attention and meaning were low. Nor were attention and meaning highly related, metaanalytic $r=-.12[-.21,-.04]$.

In other words, empirical evidence supports the MAC model's claim that boredom is an affective signal of unsuccessful attentional engagement in valued goal-congruent activity. Deficits in either attention (e.g., unsuccessful attentional engagement) or meaning (e.g., valued goal-congruent activity) are thus sufficient to induce boredom. Across a broad range of 
situations, both attention and meaning independently predict boredom, are not highly correlated and do not interact. Furthermore, boredom results when something is too easy or too hard, because both make it hard to pay attention. Like other emotions, boredom conveys information, in this case that one's current activity is not meaningful, or is too hard (or too easy), making it difficult to pay attention. Because of this, when manipulated experimentally, attention and meaning deficits result in different profiles of boredom with different downstream consequences for how people behave (Westgate and Wilson 2018). For instance, being bored because what you are doing lacks meaning feels different and has different consequences than being bored because you cannot pay attention, because they signal different problems.

\section{Reducing boredom: Restoring meaning and attention}

Why we are bored shapes what we want to do next, and helps explain why bored people make often puzzling decisions, such as choosing to self-administer painful electric shocks or turning to political extremism. In short, like pain, boredom may be unpleasant but it plays an important role in alerting us when we either do not want to (or are unable to) pay attention to what we're doing, and motivating us to change our behavior to restore attention and meaning to our lives. This may be especially powerful when it comes to moral-decision making due to boredom's aversive nature; people are highly motivated to escape boredom, even at their own cost (e.g., Dal Mas and Wittmann 2017; Wilson et al. 2014) and perhaps at the cost of others.

If boredom is caused by deficits in meaning and attention, then effective means of reducing boredom will restore those deficits. As such, there are three ways that people can effectively reduce boredom: regulating attention, regulating meaning, or switching activities altogether. Regulating attention restores the balance between cognitive resources and cognitive 
demands such that both are high (e.g., resulting in feelings of interest) or both low (e.g., resulting in feelings of enjoyment). This can be done by altering either side of the person-situation interaction. For instance, we can alter the situation to be more (or less) challenging, such as when people add time limits to otherwise overly easy tasks (Sansone et al. 1992). However, we can also alter the person side of the equation, by increasing (or decreasing) our own available cognitive resources, through long-term (e.g., skill-building) or short-term (e.g., caffeine) means. For instance, work by Silvia (2005) suggests that abstract art is boring unless you have the capacity to make sense of it; presumably an art degree would remedy this issue.

Likewise, regulating meaning involves restoring the connection between what you are currently doing and your own valued goals. For instance, helping students draw connections between their coursework and their own personal goals increases interest and achievement (Hulleman et al. 2010). The final option, rather than tinkering with the current task to make it more appropriately challenging or meaningful, is to switch tasks altogether. Activity-switching is the most commonly studied response to boredom, in part because switching activities carries with it the potential to remedy deficits of both attention and meaning simultaneously. In the next section, we discuss implications of this strategy for moral decision-making.

\section{Boredom as a moral emotion}

Thus far, we have explained how emotions matter for both moral decision-making and behavior. We have also situated boredom as one such emotion and shown that boredom is an important signal indicating a lack of meaningful attentional engagement. In this section, we posit that depending on the context, boredom can be a moral emotion and lead us to behave in both moral (and immoral) ways. 
Boredom motivates (im)moral behavior. Much research has focused on moral emotions such as anger, guilt, and disgust. Indeed, these emotions have been implicated in how morality is perceived and enforced. Prinz, in his seminal book, The Emotional Construction of Morals, argues that, "different emotions have different motivational consequences, and a token of the concept wrong will motivate us differently depending on which emotion it happens to manifest on a particular occasion" (Prinz 2007, 103). We suggest that boredom is one such emotion.

Moral benefits of boredom. In uplifting news, several studies have found associations between boredom and prosocial behavior. For instance, among 31 students asked to estimate how much money they would donate to a hypothetical educational charity in Zamibia, participants who first completed a repetitive odds-estimation task said they would donate an average of $€ 12.94$ (vs. $€ 5.73$ among participants who did not complete the task first). Likewise, among 88 students who completed a long (vs. short) estimation task and were then asked to read about a charity that was either very effective (or not very effective), participants in the longer task said they felt more bored and claimed they would donate more. However, these sample sizes are small and fall below recommendations calling for a minimum of 50 participants per cell to ensure adequate statistical power in experimental designs (Simmons, Nelson, and Simonsohn 2013).

It is also unclear whether behavioral intentions, as measured in hypothetical scenarios, translate into actual behavior; such links are notoriously weak (Ajzen and Fishbein 1977; La Piere 1934). For instance, another study finds that religious people, who typically contribute more to charity, actually appear to experience less boredom than non-religious people (van Tilburg et al. 2019). The link between actual and intended behavior may be particularly weak 
when it comes to behavior with moral implications. For instance, a recent intervention to increase sustainable food purchases in a café (Piester et al. 2020) found that almost half of customers ended up ordering a different menu item than they had told researchers they planned to purchase only moments earlier, while in line!

We examined actual prosocial behavior while simultaneously inducing boredom (Pfattheicher et al. 2020) by randomly assigning 634 participants to watch either a 5-minute video of magic tricks (control) or a 5-minute video of a rock (boredom condition). During the video participants could press up to ten available buttons: five buttons boosted the pay of another yoked participant in 10-cent increments and the other five buttons docked their pay in 10-cent increments. People could press pay-boosting buttons, or pay-docking buttons, but not both; there was no personal gain or cost to the participant of pressing any of the buttons. Participants who watched the rock video felt more bored, but were not more likely to press the pay-boosting button than participants in the control condition. In fact, rates of prosocial behavior across both conditions were very high ( $89 \%$ overall). In contrast, in another large study we found that inducing boredom experimentally did increase the extent to which people punished a wrong-doer in a third-party punishment paradigm $(n=983)$, raising punishment rates from $66 \%$ (control condition) to $76 \%$ (boredom condition). If boredom does increase prosocial behavior, the relationship may depend both on the behavior in question, and people's existing motivations.

Irresponsible behavior. Boredom has long been associated with irresponsibile behavior at school, at work, and in the polling booth. Boredom is common in schools and the workplace, and bored students and workers perform more poorly than their more engaged classmates and colleagues (Pekrun et al. 2006; Fisher 1993, 1998). For instance, cops report that they are more likely to make traffic stops when bored (Phillips 2016). Boredom has also been an inadvertent 
side effect of increasing automation (Cummings et al. 2015), including in anesthesiology and air traffic control, where lapses of attention have potentially life-altering consequences. A wellpublicized series of collisions between US naval vessels occupied headlines in summer 2019 (Faturechi, Rose, and Miller 2019); official reports attributed the mishaps to sailor fatigue while standing long watches on deck — an anonymous sailor wrote to one of the authors of this chapter stating they believed boredom played a central role in such incidents.

Boredom can also drive irresponsible or impulsive behavior in more mundane settings.

People are more like likely to speed when bored, and interventions that reduce roadway boredom also improve responsible driving (Steinberger et al. 2017). Likewise, bored people snack more (Moynihan et al. 2015; Havermans et al. 2015), and may gossip more (Yucel, Buttrick, and Westgate 2020). If boredom leads people to seek out sources of meaning, it may also inadvertently lead to political extremism. For instance, in a study of 97 visitors (71 liberal, 26 conservative) to a college campus in Ireland, liberals reported being more liberal after a boredom induction (van Tilburg and Igou 2016). There was no corresponding effect of boredom among conservatives.

Prejudice and discrimination. Boredom has also been associated with ingroup bias. In several small samples, Irish participants, after completing a boring task, favored the name Eion over Owen $(n=39)$, liked shamrock symbols more $(n=60)$, and recommended longer prison sentences for an English criminal defendant but shorter sentences for an Irish defendant $(n=90$; van Tilburg and Igou 2011). Taken together, the above work suggests that boredom can (at least sometimes) lead people to engage in irresponsible, impulsive, and immoral behaviors.

Substance use and self-harm. These effects also extend to behaviors that, while not necessarily moral, do cause harm to the self, including disturbing associations with substance use 
and self-injury. Boredom has been consistently linked to alcohol and drug use in correlational research (e.g., Weybright et al. 2015). For instance, state-level differences in boredom predict drug-related deaths across all 50 US states, even after controlling for background demographics (Baldwin and Westgate 2020). Alcohol and drug use constitute suppression strategies, a method of coping with emotion by making the emotion simply "go away" (Gross 2014). Alcohol effectively reduces boredom short-term; in experimental lab studies, people feel less bored after drinking vodka cranberry (vs plain cranberry juice; Westgate and Fairbairn 2020) cocktails. Suppression does not, ultimately, work well as an effective long-term emotion regulation strategy, however, because it does not resolve the underlying issues that produced. For instance, smoking marijuana (Block et al. 1998) actually increases boredom over time in experimental lab administration.

Both experimental and correlational research have also linked boredom explicitly to forms of self-injury and self-harm (e.g., Wilson et al. 2014). For instance, in one study, $67 \%$ of men and $25 \%$ of women asked to sit and entertain themselves with their own thoughts chose to shock themselves during this period. These effects appear specific to boredom. For instance, in an experimental follow-up, boredom increased self-administered electric shocks, particularly among those with a history of nonsuicidal self-injury, but sadness did not (Nederkoorn et al. 2016). In another experiment, $93 \%$ of participants shocked themselves while watching a boring excerpt (on repeat for an hour) from a documentary on neuroscientist Erik Kandel, whereas only $37 \%$ shocked themselves while watching the full documentary; this effect was not moderated by boredom proneness (Havermans et al. 2015).

Interpersonal cruelty and sadism. Perhaps the clearest evidence for the moral implications of boredom stems from work on interpersonal cruelty, aggression, and sadism. 
Alarmingly, boredom in life is correlated with higher sadistic tendencies $(\mathrm{r}=.37$; Pfattheicher et al. 2020). Internet trolls report higher boredom proneness, soldiers who experience more boredom during military service report behaving more sadistically towards their colleagues, and parents who experience more boredom during childcare report behaving more sadistically towards their own children. In experimental studies, inducing boredom increases the percentage of people willing to kill helpless worms for fun (i.e., by grinding them up in a coffee grinder) from $2 \%$ (control condition) to almost $18 \%$ (experimental boredom condition). And inducing boredom significantly increases the number of people willing to dock other participants' pay for their own amusement.

(Im)moral behavior as emotion regulation. People may make immoral decisions out of a genuine but misguided desire to reduce boredom. According to the Meaning and Attentional Components (MAC) model of boredom, when we are bored, we seek out challenging and/or meaningful activities (Westgate 2020; Westgate and Wilson 2018). Hence we argue that lack of meaning and attention motivate us by 1) increasing our desire for activities that happen to be (im)moral and 2) by shaping what we construe to be moral while we are bored.

People may pursue (im)moral activites as challenging and/or meaningful alternatives to boredom. For instance, attentional deficits in boredom tell us to seek ways to change stimulation in our environment; our willingness to hurt ourselves or others when bored may stem from the desire to remedy understimulation. In the above studies, for instance, excitement-seeking (but not need for meaning) mediated sadistic behavior in response to experimentally induced boredom (Pfattheicer et al. 2020). Likewise, boredom tells us to seek meaning in our actions; ingroup biases and political extremism in response to boredom may reflect such motives, as may the increased tendency to sanction moral offenders. Because meaning is inherently subjective, 
such attempts to remedy meaning deficits need not necessarily be prosocial or positive, from society's standpoint. Together, these deficits in meaning and attention draw us to engage with our environment: combined, they increase novelty-seeking (Kapoor et al. 2015; Bench and Lench 2019) and reward-sensitivity (Milyavsakaya et al. 2019). Whether these impulses are morally good or bad depends in part on whether available options are good ones.

Deficits in meaning and attention can also shape whether we perceive an action as more or less moral, thus changing how we construe morality. Just as feeling angry or disgusted may lead us to perceive certain actions as moral, feeling bored may make certain immoral actions more acceptable. For instance, we may relax norms against deviant or antisocial behaviors when bored; such tendencies may account for why bored people are more willing to kill worms, dock other participants' pay, and engage in $3^{\text {rd }}$ party punishment. By relaxing our definitions of what constitutes moral behavior, boredom may also affect our desire to act on our construals. In a situation where our only way out of feeling bored is by doing something wrong, we may come to rationalize immoral behavior. For instance, in classic work on cognitive dissonance, participants induced to lie to others about their enjoyment of a boring task subsequently came to believe their own lies (Festinger and Carlsmith 1959). Thus, we predict that boredom will lead people to rationalize potentially immoral behavior to the extent that they believe such actions will make them feel better.

Situations limit moral behavior. Whether boredom leads to anti- or prosocial behavior depends on the situation: when environments allow us to intervene and help others, we can do so. However, in situations where we are unable to help others, we may settle on inaction or worse, harm, if we believe it will reduce boredom. In such cases, boredom itself may incentivize immoral behavior. Below we consider factors that affect our abilities to act morally. 
Good choices require good options. We predict boredom will only increase antisocial behavior when prosocial options are unavailable. For instance, Pfattheicher et al. (2020) find that boredom increases antisocial behavior. However, when given a choice between pressing a button to dock other participants' pay or pressing a button to boost their pay by the same amount, people are overwhelmingly prosocial (Pfattheicher et al. 2020). When people have a prosocial option available, the effect of boredom on antisocial behavior largely disappears (except for individuals already high in dispositional sadism). In contrast, when only an antisocial option is available, boredom significantly increases the number of people who choose to take it. In cases where the environment limits our ability us to behave morally, doing nothing may result in continued boredom.

Overall, people prefer action over inaction (Albarracín et al. 2019); this tendency may be exaggerated when bored. Thus, we predict that in situations with limited options, boredom will increase prosocial behavior when taking action is positive (i.e., when only prosocial actions available), and increase antisocial behavior when taking action is negative (i.e., when only antisocial options available). For instance, classic work by Cialdini, Darby, and Vincent (1973) found that sad moods increased helping only if other positive events did not intervene. That is, if helping others was the only way to feel better, people did so, but not otherwise.

The same phenomenon plays out societally as well. In a large national study using google searches to index feelings of boredom, we found that US states that were psychologically diverse (e.g., California, Texas) experienced less boredom than states that were less diverse (e.g., Ohio, Utah). And, in turn, these states experienced fewer drug-related deaths (Baldwin and Westgate 2020). Importantly, however, this link between drug-related deaths and national boredom rates was contingent upon social ecology; in places rich in meaning and psychological diversity, 
people not only experienced boredom less frequently, but may have better alternatives available to them to reduce boredom when it occurs. In sum, doing good when bored is influenced by the opportunity to do good in the first place.

The perils and promise of deliberation. Situations may affect moral behavior in a second way, by imposing cognitive loads that influence whether we behave pro- or antisocially. The Social Heuristic Hypothesis dictates that people intuitively behave in cooperative/prosocial ways (Rand et al. 2014). Despite our intuitive prosociality, when asked to deliberate before deciding to act, people are often less cooperative. Cognitive load may differentially affect our ability to act morally depending on the type of boredom we are experiencing. When boredom is induced by high cognitive load (i.e., when we are over-stimulated), we may act in line with intuitions and behave prosocially, because we do not have the cognitive space to think through what is most beneficial to us. But in low cognitive load boredom (i.e., when we are under-stimulated), we may deliberate more and act less cooperatively or more antisocially, because we do have the cognitive space to think through what is most beneficial to us. Thus, we predict that attentional boredom due to overload is more likely to result in prosocial behavior, while attentional boredom due to underload is more likely to result in antisocial behavior.

Thus, boredom interacts with the environment; while boredom provides motivation to act, environments limit and facilitate our ability to behave in pro- or antisocial ways. Whether boredom results in moral or immoral behavior is therefore a function of how people's motivation to reduce it interacts with the options available to do so.

\section{Charting a Better Course}


In this chapter we have reviewed what boredom is, why it occurs, how it influences our moral decision-making process, and how we can re-direct ourselves when this occurs. We want to close by considering ways we can shape our environments—at work, at school, and at home - to reduce boredom and encourage moral behavior at those times when boredom is unavoidable. People cannot do good if they do not have the opportunity to do so. Boredom motivates action, which is a good thing; but environments channel the direction that action can take. By providing psychologically rich and diverse environments, we not only prevent boredom but expand the range of moral options available to people when they are bored. Societal change to improve accessibility and equality of health care, employment, education, and the humanities (including literature and the arts) is thus not only an important factor in psychological well-being, but an important factor in moral decision-making as well. By expanding citizens' ability to lead psychologically rich, interesting lives, we expand their ability to live morally consistent ones as well. 


\section{References}

Aderman, David. 1972. "Elation, depression, and helping behavior." Journal of Personality and Social Psychology 24 (1): 91-101.

Albarracín, Dolores, Aashna Sunderrajan, Wenhao Dai, and Benjamin X. White. 2019. "The social creation of action and inaction: From concepts to goals to behaviors." In Advances in Experimental Social Psychology Vol. 60, edited by James M. Olson, 223-271. Cambridge: Academic Press.

Arsenio, William F., and Martin E. Ford. 1985. "The role of affective information in socialcognitive development: Children's differentiation of moral and conventional events." Merrill-Palmer Quarterly 31 (1): 1-17.

Baldwin, Matthew., and Erin C. Westgate. 2020. "States of boredom: Downsides to being bored in the USA.” Unpublished manuscript.

Baron, Robert A., and Marna I. Bronfen. 1994. "A Whiff of Reality: Empirical Evidence Concerning the Effects of Pleasant Fragrances on Work - Related Behavior 1." Journal of Applied Social Psychology 24 (13): 1179-1203.

Baron, Robert A., Mark S. Rea, and Susan G. Daniels. 1992. "Effects of indoor lighting (illuminance and spectral distribution) on the performance of cognitive tasks and interpersonal behaviors: The potential mediating role of positive affect." Motivation and Emotion 16 (1): 1-33.

Barrett, Lisa Feldman. 2006. "Are emotions natural kinds?." Perspectives on Psychological Science 1 (1): 28-58.

Barrett, Lisa Feldman. 2017. How Emotions are Made: The secret life of the brain. Houghton Mifflin Harcourt. 
Barrett, Lisa Feldman, Ralph Adolphs, Stacy Marsella, Aleix M. Martinez, and Seth D. Pollak. 2019. "Emotional expressions reconsidered: Challenges to inferring emotion from human facial movements." Psychological science in the public interest 20(1): 1-68.

Bartlett, Monica Y., and David DeSteno. 2006. "Gratitude and prosocial behavior: Helping when it costs you." Psychological Science 17 (4): 319-325.

Batson, C. Daniel, and Laura L. Shaw. 1991. "Evidence for altruism: Toward a pluralism of prosocial motives." Psychological Inquiry 2 (2): 107-122.

Barbalet, Jack M. 1999. "Boredom and social meaning”. British Journal of Sociology 50: 631646.

Bench, Shane W., and Heather C. Lench. 2019. "Boredom as a seeking state: Boredom prompts the pursuit of novel (even negative) experiences." Emotion 19(2): 242.

Benson, Peter L. 1978. "Social feedback, self-esteem state, and prosocial behavior. " Representative Research in Social Psychology 9: 43-56.

Berlyne, Daniel E. 1960. “Conflict, arousal and curiosity.” New York, NY: McGraw-Hill. Blair, Robert James Richard. 1995. “A cognitive developmental approach to morality: investigating the psychopath.” Cognition 57 (1): 1-29.

Block, Robert I., Wesley J. Erwin, Roxanna Farinpour, and Kathleen Braverman. 1998. "Sedative, stimulant, and other subjective effects of marijuana: relationships to smoking techniques." Pharmacology Biochemistry and Behavior 59 (2): 405-412.

Bradley, Margaret M., Laura Miccoli, Miguel A. Escrig, and Peter J. Lang. 2008. "The pupil as a measure of emotional arousal ad autonomic activation." Psychophysiology 45 (4): 602-607.

Brown, Rupert, and Sabina Cehajic. 2008. "Dealing with the past and facing the future: Mediators of the effects of collective guilt and shame in Bosnia and Herzegovina." 
European Journal of Social Psychology 38 (4): 669-684.

Brown, Rupert, Roberto González, Hanna Zagefka, Jorge Manzi, and Sabina Čehajić. 2008. "Nuestra culpa: collective guilt and shame as predictors of reparation for historical wrongdoing." Journal of Personality and Social Psychology 94 (1): 75-90.

Čehajić-Clancy, Sabina, Amit Goldenberg, James J. Gross, and Eran Halperin. 2016. "Socialpsychological interventions for intergroup reconciliation: An emotion regulation perspective." Psychological Inquiry 27 (2): 73-88.

Cialdini, Robert B., Donald J. Baumann, and Douglas T. Kenrick. 1981. "Insights from sadness: A three-step model of the development of altrism as hedonism." Developmental Review 1: 207-223.

Cialdini, Robert B., Betty Lee Darby, and Joyce E. Vincent. 1973. "Transgression and altruism: A case for hedonism." Journal of Experimental Social Psychology 9 (6): 502-516.

Cialdini, Robert B., and Jim Fultz. 1990. "Interpreting the negative mood-helping literature via" mega"-analysis: A contrary view." Psychological Bulletin 107 (2): 210-214.

Cialdini, Robert B., and Douglas T. Kenrick. 1976. "Altruism as hedonism: a social development perspective on the relationship of negative mood state and helping." Journal of Personality and Social Psychology 34 (5): 907-914.

Clore, Gerald L., Karen Gasper, and Erika Garvin. 2001. "Affect as information." Handbook of Affect and Social Cognition: 121-144.

Clore, Gerald L., and Andrew Ortony. (2013). "Psychological construction in the OCC model of emotion." Emotion Review 5: 335-343.

Clore, Gerald L., and Maya Tamir. 2002. “Affect as embodied information.” Psychological Inquiry 13 (1): 37-45. 
Cohen, Dov, Richard E. Nisbett, Brian F. Bowdle, and Norbert Schwarz. 1996. "Insult, aggression, and the southern culture of honor: An" experimental ethnography."." Journal of Personality and Social Psychology 70 (5): 945.

Cohen, Dov, Richard E. Nisbett, Brian. 1994. "Self-protection and the culture of honor: Explaining southern violence.” Personality and Social Psychology Bulletin 20 (5): 551567.

Cox, T. 1980. Repetitive work. In Current Concerns in Occupational Stress, edited by C. L. Cooper \& R. Payne. London, UK: Wiley.

Cummings, Mary L., Fei Gao, and Kris M. Thornburg. 2016. "Boredom in the workplace: A new look at an old problem." Human Factors 58 (2): 279-300.

Cunningham, Michael R., Jeff Steinberg, and Rita Grev. 1980. "Wanting to and having to help: Separate motivations for positive mood and guilt-induced helping." Journal of Personality and Social Psychology 38 (2): 181-192.

Dal Mas, Dennis E., and Bianca C. Wittmann. 2017. "Avoiding boredom: Caudate and insula activity reflects boredom-elicited purchase bias." Cortex 92: 57-69.

Danckert, James, and Colleen Merrifield. 2018. "Boredom, sustained attention and the default mode network." Experimental Brain Research 236 (9): 2507-2518.

Eastwood, John D., Alexandra Frischen, Mark J. Fenske, and Daniel Smilek. 2012. "The unengaged mind: Defining boredom in terms of attention." Perspectives on Psychological Science 7 (5): 482-495.

Elpidorou, Andreas. 2017. "The moral dimensions of boredom: A call for research." Review of General Psychology 21 (1): 30-48.

Faturechi, Robert, Megan Rose and T. Christian Miller. 2019. "Years of Warnings, then Death 
and Disaster. How the Navy failed its sailors.” ProPublica. Accessed November 30, 2020: https://features.propublica.org/navy-accidents/us-navy-crashes-japan-cause-mccain/

Ferguson, Fiona, \& Sonya McLean. 2019. “Teen pointed gun at passing cars from M50

bridge "was bored and messing." Echo. Accessed November 30, 2020:

http://www.echo.ie/tallaght/article/teen-pointed-gun-at-passing-cars-from-m50-bridge-wasbored-and-messing

Festinger, Leon, and James M. Carlsmith. 1959. "Cognitive consequences of forced compliance." The Journal of Abnormal and Social Psychology 58(2): 203.

Fisher, Cynthia D. 1993. "Boredom at work: A neglected concept." Human Relations 46: 395417.

Fisher, Cynthia D. 1998. "Effects of external and internal interruptions on boredom at work: Two studies.” Journal of Organizational Behavior 19: 503-522.

Ford, Brett Q., Matthew Feinberg, Phoebe Lam, Iris B. Mauss, and Oliver P. John. 2018. "Using reappraisal to regulate negative emotion after the 2016 US presidential election: Does emotion regulation trump political action?." Journal of Personality and Social Psychology 117 (5): 998.

Gasper, Karen. 2018. "Utilizing neutral affective states in research: theory, assessment, and recommendations." Emotion Review 10 (3): 255-266.

Gasper, Karen, Lauren A. Spencer, and Danfei Hu. 2019. "Does neutral affect exist? How challenging three beliefs about neutral affect can advance affective research." Frontiers in Psychology 10.

Gendron, Maria, Debi Roberson, Jacoba Marieta van der Vyver, and Lisa Feldman Barrett. (2014a). "Cultural relativity in perceiving emotion from vocalizations.” Psychological 
Science (25): 911-920.

Gendron, Maria, Debi Roberson, Jacoba Marietta van der Vyver, and Lisa Feldman Barrett. 2014b. "Perceptions of emotion from facial expressions are not culturally universal: Evidence from a remote culture." Emotion 14, 251.

Gross, James J. 2014. "Emotion regulation: Conceptual and empirical foundations.” In Handbook of Emotion Regulation, edited by James J. Gross, 3-20. The Guilford Press.

Goetz, Thomas, Anne C. Frenzel, Nathan C. Hall, Ulrike E. Nett, Reinhard Pekrun, and Anastasiya A. Lipnevich. 2014. "Types of boredom: An experience sampling approach." Motivation and Emotion 38 (3): 401-419.

Goetz, Thomas, Anne C. Frenzel, Reinhard Pekrun, and Nathan C. Hall. 2006. "The domain specificity of academic emotional experiences." The Journal of Experimental Education 75 (1): 5-29.

Haidt, Jonathan. 2001. "The emotional dog and its rational ail: A social intuitionist approach to moral judgment." Psychological Review 108 (4): 814-834.

Haidt, Jonathan, Fredrik Bjorklund, and Scott Murphy. 2000. "Moral dumbfounding: When intuition finds no reason." Unpublished manuscript, University of Virginia: 191-221.

Havermans, Remco C., Linda Vancleef, Antonis Kalamatianos, and Chantal Nederkoorn. 2015. "Eating and inflicting pain out of boredom." Appetite 85: 52-57.

Hepach, Robert, Amrisha Vaish, Tobias Grossmann, and Michael Tomasello. 2016. "Young children want to see others get the help they need." Child Development 87 (6): 1703-1714. Hepach, Robert, Amrisha Vaish, and Michael Tomasello. 2012. "Young children are intrinsically motivated to see others helped." Psychological Science 23 (9): 967-972. https://doi.org/10.1177/0956797612440571 
Hulleman, Chris S., Olga Godes, Bryan L. Hendricks, and Judith M. Harackiewicz. 2010.

"Enhancing interest and performance with a utility value intervention." Journal of Educational Psychology 102 (4): 880.

Hume, David. 1896. A Treatise of Human Nature. Oxford: Clarendon Press.

Isen, Alice M., and Paula F. Levin. 1972. "Effect of feeling good on helping: Cookies and kindness." Journal of Personality and Social Psychology 21: 384 -388.

Iyer, Aarti, Toni Schmader, and Brian Lickel. 2007. "Why individuals protest the perceived transgressions of their country: The role of anger, shame, and guilt." Personality and Social Psychology Bulletin 33: 572-587.

Kapoor, Komal, Karthik Subbian, Jaideep Srivastava, and Paul Schrater. 2015. "Just in time recommendations: Modeling the dynamics of boredom in activity streams." In Proceedings of the eighth ACM international conference on web search and data mining, 233-242. New York, NY: ACM.

Kohlberg, Lawrence. 1964. "Development of moral character and moral ideology”.Review of Child Development Research 1: 383-431.

Kohlberg, Lawrence. 1976. "Moral stages and moralization: The cognitive-developmental.” In Moral development and behavior: Theory, research and social issues, 31-53. Holt, Rinehart \& Winston.

Lindquist, Kristen A., Tor D. Wager, Hedy Kober, Eliza Bliss-Moreau, and Lisa Feldman Barrett. 2012. "The brain basis of emotion: A meta-analytic review." The Behavioral and Brain Sciences 35 (3): 121.

Locke, Edwin A., and Gary P. Latham. 1990. A theory of goal setting and task performance. Englewood Cliffs, NJ: Prentice. 
Lotz, Sebastian, Tyler G. Okimoto, Thomas Schlösser, and Detlef Fetchenhauer. 2011. "Punitive versus compensatory reactions to injustice: Emotional antecedents to third-party interventions." Journal of Experimental Social Psychology 47: 477-480.

Lyubomirsky, Sonja, Laura King, and Ed Diener. 2005. "The benefits of frequent positive affect: Does happiness lead to success?.” Psychological Bulletin 131; 803.

Milyavskaya, Marina, Michael Inzlicht, Travis Johnson, and Michael J. Larson. 2019. "Reward sensitivity following boredom and cognitive effort: A high-powered neurophysiological investigation." Neuropsychologia 123: 159-168.

Montada, Leo, and Angela Schneider. 1989. "Justice and emotional reactions to the disadvantaged." Social Justice Research 3: 313-344

Moynihan, Andrew B., Wijnand AP Van Tilburg, Eric R. Igou, Arnaud Wisman, Alan E. Donnelly, and Jessie B. Mulcaire. 2015. "Eaten up by boredom: Consuming food to escape awareness of the bored self." Frontiers in Psychology 6: 369.

Nederkoorn, Chantal, Linda Vancleef, Alexandra Wilkenhöner, Laurence Claes, and Remco C. Havermans. 2016. "Self-inflicted pain out of boredom." Psychiatry Research 237: 127-132.

Nichols, Shaun. 2002. "Norms with feeling: Towards a psychological account of moral judgment." Cognition 84: 221-236.

Nichols, Shaun. 2004. Sentimental Rules. Oxford University Press.

O'Malley, Michael N., and Lester Andrews. 1983. "The effect of mood and incentives on helping: Are there some things money can't buy?" Motivation and Emotion 7: $179-189$.

Ortony, Andrew, Gerald L. Clore, and Allan Collins. 1988. The Cognitive Structure of Emotions. New York: Cambridge University Press.

Pekrun, Reinhard, Andrew J. Elliot, and Markus A. Maier. 2006. "Achievement goals and 
discrete achievement emotions: A theoretical model and prospective test." Journal of Educational Psychology 98 (3): 583.

Peters, Ellen, Daniel Västfjäll, Tommy Gärling, and Paul Slovic. 2006. “Affect and decision making: A "hot" topic." Journal of Behavioral Decision Making 19 (2): 79-85.

Pfattheicher, Stefan, Ljiljana B. Lazarević, Erin C. Westgate, and Simon Schindler. 2020. "On the relation of boredom and sadistic aggression." Journal of Personality and Social Psychology.

Piaget, Jean. 1960. "Problems of the social psychology of childhood." In Sociological Studies edited by J. Smith, 287-318. Routledge.

Piester, Hannah E., Christine M. DeRieux, Jane Tucker, Nicholas R. Buttrick, James N. Galloway, and Timothy D. Wilson. 2020. ““I'll try the veggie burger”: Increasing purchases of sustainable foods with information about sustainability and taste." Appetite 155: 104842.

Prinz, Jesse. 2006. “The emotional basis of moral judgments." Philosophical Explorations 9 (1), $29-43$.

Prinz, Jesse. 2007. The emotional construction of morals. Oxford University Press.

Prinz, Jesse, \& Shaun Nichols. 2010. "Moral Emotions". In The Moral Psychology Handbook, $111-146$.

Rand, David G., Alexander Peysakhovich, Gordon T. Kraft-Todd, George E. Newman, Owen Wurzbacher, Martin A. Nowak, and Joshua D. Greene. 2014. “Social heuristics shape intuitive cooperation." Nature Communications 5 (1): 1-12.

Sansone, Carol, Charlene Weir, Lora Harpster, and Carolyn Morgan. 1992. «Once a boring task always a boring task? Interest as a self-regulatory mechanism." Journal of Personality and Social Psychology 63: 379-390. 
Siegel, Erika H., Molly K. Sands, Wim Van den Noortgate, Paul Condon, Yale Chang, Jennifer Dy, Karen S. Quigley, and Lisa Feldman Barrett. 2018. "Emotion fingerprints or emotion populations? A meta-analytic investigation of autonomic features of emotion categories." Psychological Bulletin 144 (4): 343-393.

Silvia, Paul J. 2005. "What is interesting? Exploring the appraisal structure of interest." Emotion 5: 89.

Simmons, Joseph P., Leif D. Nelson, and Uri Simonsohn. "Life after p-hacking." In Meeting of the society for personality and social psychology, New Orleans, LA: 17-19.

Smith, Adam. 1976. "The Glasgow Edition of the Works and Correspondence of Adam Smith: I: The Theory of Moral Sentiments edited by D. D. Raphael and A. L. Macfie.

Steinberger, Fabius, Ronald Schroeter, and Christopher N. Watling. 2017."From road distraction to safe driving: Evaluating theeffects of boredom and gamification on driving behaviour, physiological arousal, and subjective experience." Computers in Human Behavior 75: 714726.

Storbeck, Justin, and Gerald L. Clore. 2008. "Affective arousal as information: How affective arousal influences judgments, learning, and memory." Social and Personality Psychology Compass 2 (5): 1824-1843.

Tamir, Maya, and Brett Q. Ford. 2012. "When feeling bad is expected to be good: Emotion regulation and outcome expectancies insocial conflicts." Emotion 12 (4): 807.

Van Doorn, Janne, Marcel Zeelenberg, and Seger M. Breugelmans. 2014. "Anger and prosocial behavior." Emotion Review 6 (3): 261-68.

Van Tilburg, Wijnand AP, and Eric R. Igou. 2011. "On boredom and social identity: A pragmatic meaning-regulation approach." Pesonality and Social Psychology Bulletin 37 
(12): 1679-1691.

Van Tilburg, Wijnand AP, and Eric R. Igou. 2012. "On boredom: Lack of challenge and meaning as distinct boredom experiences." Motivation and Emotion 36 (2): 181-194.

Van Tilburg, Wijnand AP, and Eric R. Igou. 2017. "Boredom egs to differ: Differentiation from other negative emotions." Emotion 17 (2): 309.

Van Tilburg, Wijnand AP, and Eric R. Igou. 2016. "Going to political extremes in response to boreom." European Journal of Social Psychology 46 (6): 687-699.

van Tilburg, Wijnand AP, and Eric R. Igou. 2017. "Can boredom help? Increased prosocial intentions in response to boredom." Sef and Identity 16 (1): 82-96.

van Tilburg, Wijnand AP, Eric R. Igou, Paul J. Maher, Andrew B. Moynihan, and Dwn G. Martin. 2019. "Bored like Hell: Religiosity reduces boredom and tempers the quest for meaning." Emotion 19 (2): 255.

Vitaglione, Guy D., and Mark A. Barnett. 2003. "Assessing a new dimension of empathy: Empathic anger as a predictor of helpingand punishing desires." Motivation and Emotion 27 (4): 301-325.

Westgate, Erin C. 2020. "Why Boredom is Interesting." Current Directions in Psychological Science 29 (1): 33-40.

Westgate, Erin C., and Catherine Fairbairn. 2020. "Buzzed, but not bored: How boredom leads to "bad" behavior." Unpublished manuscript.

Westgate, Erin C., and Brianna Steidle. 2020. "Lost by definition: Why boredom matters for psychology and society." Social and Personality Psychology Compass: e12562.

Westgate, Erin C., and Timothy D. Wilson. 2018. "Boring thoughts and bored minds: The MAC model of boredom and cognitive engagement." Psychological Review 125 (5): 689. 
Weyant, James M. 1978. "Effects of mood states, costs, and benefits on helping." Journal of Personality and Social Psychology 36 (10): 1169.

Weybright, Elizabeth H., Linda L. Caldwell, Nilam Ram, Edward A. Smith, and Lisa Wegner. 2015. "Boredom prone or nothing to do? Distinguishing between state and trait leisure boredom and its association with substance use in South African adolescents." Leisure Sciences 37 (4): 311-331.

Wilson, Timothy D., David A. Reinhard, Erin C. Westgate, Daniel T. Gilbert, Nicole Ellerbeck, Cheryl Hahn, Casey L. Brown, andAdi Shaked. 2014. "Just think: The challenges of the disengaged mind." Science 345 (6192): 75-77.

Yucel, Meltem, Robert Hepach, and Amrisha Vaish. 2020. "Young children and adults show differential arousal to moral and conventiona transgressions." Frontiers in Psychology 11 (548).

Yucel, Meltem, Nicholas Buttrick, \& Erin C. Westgate. Unpublished data. "Gossip-asentertainment: Bored people gossip more." 